\title{
O PROBLEMA DO ETHOS DA ESCRITA DE SI EM MONTAIGNE E EM PETRARCA: DO ENSAIO À EPÍSTOLA
}

\author{
Sergio Xavier Gomes de Araujo* \\ sxaraujo@gmail.com
}

RESUMO Montaigne insiste ao longo dos Ensaios em seu desprezo pela retórica. Mas como procuraremos mostrar aqui, sua "forma natural" inscreve-se em grande medida dentro dos termos da própria retórica, sob uma mobilização particular dos preceitos e convenções tradicionalmente apropriados à escrita em primeira pessoa, especialmente aqueles que regulavam o sermo familiaris, gênero recuperado pela primeira vez na Renascença por Petrarca. Retomamos assim, para desenvolvê-la, a fecunda intuição de Hugo Friedrich que, em sua clássica obra sobre os Ensaios de Montaigne, aponta o seu parentesco com a forma epistolar de Petrarca, sem, porém, acompanhá-lo quando distancia o ensaio da epístola familiar, por entendê-lo como marco de ruptura com os procedimentos da retórica e, assim, com toda a prosa artisticamente trabalhada do humanismo.

Palavras-chave Montaigne, Petrarca, Sêneca, Ensaio, Epístola.

ABSTRACT Montaigne insists throughout the course of the Essays on his disdain for rhetoric. But as we try to expose here, his "natural form" includes itself to a large extent in the terms of rhetoric itself, under a particular usage of the precepts and conventions traditionally appropriate to the discourse in first person, especially those which regulated the sermo maio de 2012 e aprovado em 25 de julho de 2012. 
familiaris, genre recuperated for the first time in the Renaissance by Petrarch. We retake, in order to develop it, the fruitful intuition of Hugo Friedrich in his classical work about Montaigne's Essays, indicating its kinship with Petrarch's epistolary form, without, however, following him when he moves the essay away from the familiar epistle by interpreting the essay as a rupture with the rhetorical procedures and therefore with all the artistically worked prose of humanism.

Keywords Montaigne, Petrarch, Seneca, Essay, Epistle.

\section{I}

Em seu clássico estudo sobre os Ensaios de Montaigne destacado particularmente pelo exame das relações destes com a produção literária da Renascença, Hugo Friedrich nos mostra que o interesse que movera Petrarca, pela investigação de sua personalidade profana e autônoma ${ }^{1}$ - especialmente no caso do Secretum e de suas correspondências reunidas nas Familiares e nas Seniles - o situa no ponto de partida de uma linha que nos leva diretamente ao autorretrato dos Ensaios, com seu sentido mais profundo, contudo, da própria individualidade. Desse modo, ao examinar o estilo ensaístico de Montaigne, mais adiante Friedrich postula seu parentesco com a escrita epistolar do primeiro grande representante do humanismo renascentista nos volumes das cartas familiares - Rerum Familiarum libri. A "forma aberta" da epístola familiar, segundo ele, teria servido de inspiração ao ensaio, pondo-se já bem antes deste, segundo a tradição, como gênero mais adequado à escrita em primeira pessoa, servindo já à "manifestação livre da consciência individual"2. Mas Friedrich insiste, sobretudo, na diferença que marcaria ruptura radical entre os dois. O ensaio se distinguiria por fundar-se numa consciência bem mais aguda da singularidade irredutível de seu objeto, desprendendo-se do recurso às convenções codificadas pela retórica clássica, para servir ao conhecimento empírico e à representação da natureza particular do eu de seu autor. O programa de Montaigne seria, assim, para Friedrich, absolutamente incompatível com os "esquemas literários" e as "noções livrescas", nas quais Petrarca ainda buscava acesso à sua própria personalidade, recuperando a 
forma clássica da carta $^{3}$. Com efeito, ao tomar a si mesmo como matéria, Montaigne teria compreendido bem melhor do que o italiano os riscos de comprometer a veracidade de sua representação, de sorte que, enfim, sua proximidade com a forma epistolar de Petrarca não ultrapassaria os termos de uma certa afinidade de caráter superficial.

Do estudo de Hugo Friedrich retemos aqui, especialmente, a ênfase no parentesco que liga as obras dos dois autores por seu intento e forma, ressaltando, contudo, parecer-nos precipitado e demasiado simplificador o modo como diferencia o ensaio da epístola, concebendo aquele como escrita espontânea, destituída de arte, adequada ao registro fiel o quanto possível das manifestações livres da subjetividade de seu autor. De fato, o intérprete separa desse modo a obra de Montaigne do domínio em que se dava toda a produção humanística de seu tempo, assimilando-a, no limite, a uma noção de método intelectual, consolidado, como nos diz, enquanto meio mais eficaz para o conhecimento do homem do que qualquer metafísica ${ }^{4}$.

A tese de Friedrich situa-se numa corrente bastante bem assentada na tradição do comentário - que remonta à obra seminal de Pierre Villey e passa pelo clássico capítulo que Eric Auerbach dedica a Montaigne em seu Mimesis concentrada em geral, na noção de mimese da natureza particular do indivíduo como chave para a compreensão dos Ensaios. Tal corrente tende a tomar como base uma interpretação bastante literal da "Advertência ao leitor", o texto de apresentação situado na primeira página do primeiro volume. Montaigne nos diz aí que não pretende mais do que retratar-se em seu livro em sua maneira "simples, natural e ordinária, sem esforço e artifício: porque é a mim que pinto" ("Advis au Lecteur", 3).

Mas a despeito da riqueza - ainda longe de ser superada - e importância inconteste desses estudos sobre os Ensaios, seu pressuposto da ideia de um eu como realidade objetiva a ser representada já foi combatido, como se sabe, por autores que pautaram suas leituras, por sua vez, na crítica cética da "Apologia de Raymond Sebond", atentando para as contradições constitutivas que perpassam o discurso dos Ensaios. Representativas dessa outra corrente são as obras de Frederic Brahami, Jean Yves Pouilloux e Terence Cave, afirmando, cada um a seu próprio modo, a inanidade do eu nos Ensaios ${ }^{5}$.

3 Idem.

4 Friedrich, H. op. cit., p. 372.

5 Afastando-nos de Friedrich, nossa leitura se aproxima mais da posição de André Tournon do que da dos que concluem pela constatação reiterada nos Ensaios da fraqueza da razão e da ignorância humana a inanidade do eu e da razão. Com efeito, concentrando-se também ele no conteúdo crítico que atravessa e constitui o livro, Tournon não o reduz, porém, a um discurso de segundo grau que se esgotaria totalmente 
Sem pretender adentrar em tais questões, reforçamos a ideia da pintura de si como motivação primeira do discurso de Montaigne, rechaçando, porém, a noção do eu como natureza individual compreendida empiricamente como objeto de uma mimese. É verdade que Montaigne reitera e desenvolve em diversas ocasiões seu desprezo pelos artifícios de linguagem a partir do prólogo de sua obra, entretanto, como procuraremos mostrar, o faz em grande medida dentro dos termos da retórica mesma. Com efeito, sob a égide do autorretrato de sua natureza particular ele proclama com ênfase seu anseio de autonomia em relação aos preceitos e regras de ação preestabelecidos, apontando para além da imitação emulativa dos antigos. Mas é, porém, como bom rebento da tradição humanista e do interior dela mesma que "empreende a transgressão de seus limites"6, aplicando ao seu próprio modo muitas das mesmas tópicas utilizadas por Petrarca, que cerca de dois séculos antes, já empreendera descrever-se. Longe assim, de tomá-la como obstáculo à sua efetivação, o autorretrato de Montaigne opera no âmbito da "invenção" literária, enraizado no terreno ético e retórico do humanismo; retomando e transformando convenções e preceitos previstos pela tradição clássica como adequados ao discurso em primeira pessoa, especialmente os que se ligam à arte epistolar. Propomos assim outra leitura do texto que serve de porta de entrada dos Ensaios, a "Advertência ao leitor", à luz da carta proemial das Familiares de Petrarca, para em seguida examinarmos a maneira como Montaigne aborda o tema de seu repúdio à retórica no capítulo "Da Educação das Crianças".

Optando por caminho diverso daquele apontado por Friedrich, detendonos com mais vagar nos elementos que ligam a escrita pessoal de Montaigne à epístola de Petrarca - conforme o fizeram os estudos de Marc Fumaroli ${ }^{7}$ - , sugerimos a maior fecundidade do tema, considerando necessário, para

na crítica das opiniões herdadas. Para ele o texto mantém um significado positivo como enunciação de juízos e de pensamentos, que, conquanto destituída de qualquer pretensão à verdade, explicita um lugar a partir do qual se fala, assim como a consciência de sua origem e de seu autor. É preciso, enfatiza o comentador, relacionar seu ceticismo com sua prática do ensaio em sua intenção sempre reafirmada de "regrar" seu pensamento e sua vida conforme o exercício das faculdades do juízo, sob a plena consciência de seu caráter contingente: "O autorretrato só é, pois, a mais manifesta figura do trabalho constitutivo do ensaio: o tipo de redução fenomenológica pela qual a investigação se reorienta do objeto, bem ou mal conhecido, para o sujeito que conhece, do veredicto pronunciado sobre tal fato para a instância de julgamento que o pronuncia (...)". Dessa perspectiva, os Ensaios deixam entrever as linhas de uma filosofia de alcance totalmente novo, fundada na fidelidade a si e na busca do exercício autônomo de suas faculdades intelectuais: "seu julgamento pronuncia veredictos seguros, teremos a oportunidade de constatar; e nada autoriza-nos a negligenciar este aspecto de sua obra.” Tournon, A. Montaigne, p. 114. Sobre o assunto ver Birchal, T. O Eu nos Ensaios de Montaigne, p. 123-211.

6 Cardoso, S. "Montaigne uma ética para além do humanismo", p. 265.

7 Fumaroli, M. "Genèse de l'épistolographie classique: rhétorique humaniste de la lettre"; ver "Les Essais de Montaigne: l'éloquence du for intérieur". 
uma melhor compreensão da forma do ensaio montaigniano em sua natureza e desígnios específicos, abordá-la em suas relações com a tradição humanista em que se insere e não enquanto expressão de uma ruptura radical com ela.

Entendemos, assim, a empresa do autorretrato em Petrarca e em Montaigne como levada a cabo essencialmente no plano artístico da constituição do próprio ethos de autor, ou, em outras palavras, da construção discursiva do próprio caráter como digno de confiança mediante o uso de procedimentos disponibilizados pela tradição literária clássica ${ }^{8}$. De fato, tomando a si próprios como matéria, ambos reclamam cada um a seu modo, a autoridade dos antigos e movem-se, basicamente, dentro de um mesmo universo de tópicas herdado da moralidade clássica, esforçando-se por legitimar sua forma pessoal; procurando enfim oferecer sua própria imagem como prova ética persuasiva - pistei - de modo a garantir a adesão dos leitores. Mas em suas apropriações diversas da herança clássica, implicam relações distintas com o leitor consubstanciando-se em figuras também distintas de cultura e de disciplina da vida moral, emblemáticas respectivamente do período de constituição do projeto humanista e de sua fase mais tardia, quando seus métodos, centrados na imitação dos antigos, já institucionalizados em toda a Europa degeneravam em mero formalismo vazio e pedantesco ${ }^{9}$. Como se verá, em sua crítica aos métodos humanistas Montaigne promove menos um rompimento com esta tradição do que uma recuperação e radicalização de seus postulados originais, voltados para a excelência dos modelos do passado com vistas à formação de agentes morais livres no presente e em plena posse do uso das próprias faculdades ${ }^{10}$.

8 O ethos define-se na Retórica de Aristóteles como uma das três fontes das pisteis, provas de persuasão, ao lado do logos e do pathos. Um orador persuade pelo ethos quando oferece a imagem de seu próprio caráter como prova ética favorável aos seus argumentos: "toda vez que o discurso é pronunciado de tal modo a tornar o orador digno de confiança". Aristóteles sublinha o caráter de construto do ethos, enquanto prova "entécnica" elaborada no interior das técnicas discursivas. Assim, ao atentar para a importância do ethos, "acreditamos mais e bem mais depressa em pessoas honestas", cuida de distinguir essa honestidade que é efeito de persuasão e parte da arte retórica, da autoridade que um orador pode extrair de seus atos precedentes ao discurso: "É, porém, necessário que esta confiança seja resultado do discurso e não de uma opinião prévia sobre o caráter do orador" [I, 1356a 1-13]. O ethos responde por um elemento central da arte retórica, ou seja, sua essência cívica, penetrada da ética; praticada por cidadãos enquanto cidadãos. De Aristóteles aos tratados latinos, os procedimentos discursivos da persuasão estão longe de reduzir-se à eficácia da argumentação lógica, ou à adequação à irracionalidade do auditório, para manipular suas emoções, mas têm como procedimento crucial a conquista da confiança dos ouvintes. Pondo em jogo a fiabilidade, o ethos implica na construção de uma relação de identidade de opiniões e de crenças - homonoia - entre o orador e auditório, na qual aquele autoriza seu próprio discurso, apresentando-se como alguém que age, fala e pensa segundo a virtude.

9 Garin, E. "L' Imitation et la pedanterie", p. 99-105.

10 Garin, E. L'Education de l'homme moderne, p. 103; Cardoso S., op. cit., p. 263. 


\section{II}

Na carta proemial de suas Familiares Petrarca assim enuncia o intento de descrever-se: "Não fiz quase nada além de dar a conhecer aos meus amigos os estados de minha alma." Define seu epistolário como "imagem de minha alma" - animi mei effigiem - e "retrato de minhas capacidades" - ingenii mei simulacrum - composto em sua maior parte de textos escritos em tom familiar - familiariter - ou íntimo, numa "narração simples e não elaborada". ${ }^{11}$ Petrarca articula aí alguns dos topoi clássicos fundamentais que regulavam a escrita epistolar, conforme aparecem de modo disperso nas correspondências de Cícero e de Sêneca, dois dos mais influentes modelos do gênero. Próxima ao diálogo - sermo - o estilo da carta devia imitar a maneira informal da conversa entre amigos, evitando, por princípio, o excesso de artifícios dos discursos pronunciados nos fóruns e assembleias. Trata-se assim de arte que tem por finalidade específica afetar o fácil e o não elaborado, constituindo a imagem dos interlocutores como verazes e sinceros. Distingue-se mais propriamente como sermo familiaris, devendo ser rico na descrição dos caracteres de quem escreve, já que se pode dizer que cada interlocutor redige a carta como retrato do próprio ânimo ${ }^{12}$. Sêneca atribui ao sermo o ofício de ensinar - docere propondo a carta como forma por excelência do discurso filosófico, definido este como "bonum consilium": "Muito mais aproveita a conversa, pois que subrepticamente se imiscui no ânimo."13

Recuperando a tradição, Petrarca se diz impelido pela "afeição dos amigos" - caritas amicorum -, dignificando sua escrita pessoal como cumprimento de importante obrigação moral, de não deixar jamais de respondê-los e de bem aconselhá-los "de que nem a excusa de minhas múltiplas ocupações me pode liberar." ${ }^{14}$ É desta perspectiva que destaca o quanto sua forma se distancia da excelência dos modelos clássicos. Afetando modéstia, reconhece que os escritos que compõem seu epistolário formam um panorama diversificado a tal ponto que chega por vezes a contradizer-se e diferir de si próprio ${ }^{15}$. Como esclarece, teria sido bem mais fácil para os antigos alcançar a beleza de uma

11 Petrarca, Fam. I, 1, 33.

12 Estes preceitos aparecem no tratado De elocutione de Demétrio, num pequeno excurso dedicado ao tema; que, conquanto breve, trata de uma das raras preceptivas do gênero. De fato, ao menos no que concerne às fontes que chegaram até nós, a escrita epistolar jamais foi tida na Antiguidade como objeto de uma arte autômoma: fazia parte das formas não abrangidas de modo sistemático pelos manuais de retórica. Os preceitos afirmados no tratado de Demétrio, contudo, aparecem de maneira dispersa e regulam as cartas de Cícero e de Sêneca. Tin, E. A Arte de escrever cartas, p. 18.

13 Sêneca, Cartas a Lucílio, 38, I.

14 Petrarca, op. cit: I, 1, 45.

15 Idem, 30. 
unidade de disposição, já que em geral teriam de atender somente a um só ou a poucos. Já ele, por sua vez, tivera de endereçar-se a um grande e diversificado número de correspondentes, sendo forçado a tornar proveitosas suas cartas a caracteres os mais diferenciados. ${ }^{16}$

Com efeito, é conferindo importância capital ao topos da adaptação e solicitude para com a identidade específica dos destinatários que Petrarca sanciona o caráter insólito de sua forma ${ }^{17}$ : "O primeiro cuidado dos que escrevem é o de estar atento àquele para quem se escreve; esta é, com efeito, a única maneira de compreender não só a matéria, mas também o tom e as restantes circunstâncias da carta." ${ }^{18}$ Desse modo manipula os elementos do gênero antigo, articulando-os aos objetivos do projeto intelectual que atravessa sua obra como um todo. O colóquio privado ou íntimo travado com vários interlocutores ao longo das Familiares promove a constituição de uma pequena comunidade entre os que se devotavam em sua época às bonna litterae. Afinal, conquanto diversificados, os destinatários que Petrarca forja para si têm em comum o fato de partilharem com ele a mesma convicção acerca da dignidade superior da cultura clássica e latina - em geral, oradores, poetas e patronos e o repúdio à concepção do saber e de seus métodos conforme a Escolástica medieval. No âmbito dessa comunidade literária ou res publica das letras, para ficarmos com a célebre expressão de Eugenio Garin - eminentemente textual, bem entendido -, Petrarca constitui sua autoridade moral, falando nas cartas como intelectual laico, escritor, poeta e filósofo. Como se sabe, compõe então a figura exemplar de vida intelectual e de aspiração à sabedoria que iria consolidar-se como paradigmática para os autores do Quatroccento $^{19}$.

16 Idem, 20.

17 A partir dessa consideração crucial Nancy Struever critica a interpretação de Thomas Greene em seu The Light of troy. Segundo a autora Greene reduz o caráter inovador do estilo pessoal de Petrarca nas epístolas ao identificá-lo com a emergência de um eu autônomo. De fato, sublinha Struever, o estilo pessoal das cartas qualifica antes de tudo a relação de amizade e se constitui como tal no âmbito da interlocução íntima ou familiar com o outro. Struever, N., Theory as practice: Ethical Enquiry in the Renaissance, p. 11.

18 "É preciso endereçar-se de uma maneira a um homem corajoso, de uma outra a um covarde; de uma outra a um homem jovem inexperiente de uma outra a um velho que possui grande experiência; de uma outra àquele que a prosperidade torna orgulhoso, de uma outra àquele que a adversidade abate; de uma outra maneira, enfim, ao estudioso ilustre em engenho e obras, de uma outra àquele que é incapaz de compreender temas demasiado elevados." Petrarca, op. cit., 29.

19 Segundo Ugo Dotti a escrita das cartas de Petrarca responde diretamente ao seu projeto intelectual: "O escritor deseja, sim, fazer saltar de seu epistolário o retrato do sábio, mas na verdade, do sábio que deseja sê-lo, ainda muito amarrado a paixões ou ilusões não definitivamente domadas." Dotti, U., Vida de Petrarca, p. 511. Na curta autobiografia da "Epístola à Posteridade" - redigida originalmente para servir como uma espécie de prefácio às Seniles, que reúnem as cartas da velhice - é pela fama e excelência de suas obras que Petrarca legitima o ato de endereçar-se a leitores distanciados no espaço e no tempo para falar de si sem que se afigurasse com isso como orgulhoso: "Talvez algo sobre mim tenha sido ouvido por ti (...) e isto talvez desejarás: conhecer que tipo de homem fui ou que obras produzi, aquelas, especialmente, cuja 
De fato, como sublinha Nancy Struever ${ }^{20}$, as Familiares afirmam-se como espaço discursivo típico da investigação moral, ética e literária em que a tradição humanista ganharia forma, alheia aos métodos estabelecidos nas Universidades. A epístola familiar se consolida ao longo dos séculos XV e XVI como uma das formas de expressão mais peculiares do humanismo, largamente empregada de Coluccio Salutati a Angelo Poliziano e Lorenzo Valla; de Erasmo a Justus Lipsius ${ }^{21}$. No capítulo "Consideração sobre Cícero" Montaigne declara, por sua vez, que a teria adotado de bom grado caso tivesse um "endereço forte e amigo" a quem dirigir-se, como tivera outrora com Étienne de La Boétie (I, 40, 252). ${ }^{22}$

De todo modo, embora destituído de um interlocutor determinado Montaigne não deixa de mobilizar os mesmos preceitos que Petrarca, situando os Ensaios, de modo bastante particular, no plano da maneira simples e privada do sermo familiaris, ao apresentar a obra no texto proemial da "Advertência ao leitor" quando de sua primeira publicação em 1580. Declara então que seu livro é antes de tudo obra de "boa fé", tendo como mote fundamental a empresa de retratar-se em sua "maneira simples, natural e ordinária", conforme já vimos. Como nos diz: "Se fosse para buscar o favor do mundo me paramentaria melhor e me apresentaria em comportamento mais estudado". Seu discurso possui "natureza "doméstica e privada", voltada apenas para alguns "parentes e amigos" (“Advis au Lecteur", 3).

O capítulo "Da Educação das crianças" 23 é um dos muitos capítulos em que Montaigne retorna ao tema de seu desprezo pela retórica ao longo da

fama tenha alcançado a ti." Petrarca, "Epístola à Posteridade", I, In: Enenkel, Modelling the Individual, p. 243-283.

20 Struever, N. Theory as Practice: Ethical Inquiry in the Renaissance, p. 14-23.

21 Como observa Fumaroli, apesar de cultuá-la, o humanismo reitera o luto já afirmado na Idade Média da oratio à maneira de Cícero e de Demóstenes - que remonta a Tácito em seu 'Diálogo dos Oradores' -, dada a ausência de espaços institucionais propícios ao discurso oral de intervenção política direta - com exceção do regime republicano florentino de inícios do século XV e, no que diz respeito às monarquias, em seus períodos de crise, como foi o caso da França da segunda metade do século XVI, assolada pelos conflitos religiosos. De fato, o gênero da epístola familiar foi domínio do único grande debate da época sobre a prosa, frequentemente levado a cabo sob a forma mesma de cartas, opondo os que postulavam a imitação estrita de Cícero como único modelo aos ecléticos, que defendiam, por sua vez, a variedade dos modelos, com vistas a estabelecer o melhor estilo latino (Fumaroli, M. op. cit., p. 886). Sobre isso ver também Mesnard, P. "Le commerce épistolaire, comme expression sociale de l'individualisme Humaniste."

22 As citações dos Ensaios de Montaigne seguem a Edição Villey-Saulnier dos Essais (PUF). As referências trazem, em alagarismos romanos, o número do livro e em algarismos arábicos o capítulo e a página da referida edição.

23 Alguns capítulos dos Ensaios cumprem propriamente a finalidade proclamada na "Advertência", de endereçar-se a amigos e parentes, chegando a constituir-se efetivamente como epístolas, destinados em geral a damas de corte de famílias às quais Montaigne era bastante ligado. "Da Educação das crianças" está entre estes, assim como "Da Afeição dos pais pelos filhos", o primeiro dirigido a Diane de Foix, condessa de Gurson, dedicado à criança de que estava grávida e o segundo à Madame D 'Estissac. Sobre esse assunto ver Goyet, F. "Montaigne and the Notion of Prudence". 
obra. Explora-o, neste caso, em contexto particularmente significativo, com a apresentação de uma nova maneira para a educação das crianças, contraposta àquela institucionalizada em seu tempo sob a égide do humanismo. $\mathrm{O}$ eixo fundamental do ensaio é da oposição entre a figura do sçavant, possuidor de ciência e arte e a do homem habil, destacado não por um saber escolar e teórico, mas como detentor de sabedoria prática (I, 26, 150). Com vistas à formação deste último, Montaigne exige uma nova conduta por parte do preceptor, acusando de exagerada e inútil a valorização humanística das artes da palavra. Sua tarefa fundamental não seria a de transmitir a autoridade das grandes obras e preceitos da Antiguidade, mas a de fazer a alma que tiver nas mãos "experimentar as coisas - [gouster les choses] -, escolhê-las e discerni-las por si mesma" (Ibidem). Recomenda assim que o preceptor "lhe peça contas não apenas das palavras de sua lição, mas sim do sentido e da substância, e que julgue sobre o benefício que tiver feito não pelo testemunho de sua memória, mas sim pelo de sua vida" (I, 26, 151).

Desse modo, em contraste com a figura do homem habil ou de juízo que assimila o conteúdo das lições dos antigos para correção dos costumes e do entendimento, conforma-se o ethos vicioso do sçavant como contra exemplo, dono de uma cultura livresca de pura ostentação, cuja finalidade resumese a "encher a memória" [remplyr la memoire] (Ibidem). A prática que o caracteriza, da imitação servil e puramente exterior dos modelos, Montaigne vincula à metáfora da má digestão: "O estômago não realizou sua operação se não fez mudar a característica e a forma do que lhe deram para digerir" (Ibidem). A boa expressão do discurso no homem habil, por seu turno, não resulta do talento nas artes da palavra, mas da boa assimilação de sua matéria pelo espírito; provindo naturalmente da 'imaginação viva e clara' que possui acerca daquilo de que fala. (I, 26, 168) Montaigne, portanto, desqualifica uma a uma, no ensaio, as artes da palavra - gramática, retórica, poesia e dialética - , tomando-as em primeiro plano como alheias ao ideal que pretende obter de sua proposta pedagógica de tornar-se "melhor e mais sensato" (I, 26, 152168).

Mas com isso ele apenas aprofunda uma tendência crítica já dada no âmbito mesmo do humanismo inerente ao elogio da imitatio dos antigos. Como salienta Eugenio Garin ${ }^{24}$, em seu vínculo constitutivo com os estudos das Letras clássicas, o programa humanístico teve como alvo primordial desde suas origens a boa formação moral e a liberação das energias criadoras 
dos homens, de modo que seus representantes se mostraram sempre atentos para que a proposição dos modelos clássicos funcionasse não no sentido da produção de cópias, mas no do estímulo à realização da própria excelência em afirmar-se em sua autonomia. É o que se vê, por exemplo, no elogio dos estudos da eloquência que Petrarca desenvolve na carta 9 do primeiro livro das Familiares. Exalta então as qualidades do estilo - lexis - em que se exprimem as virtudes da alma bem formada contrárias às que denotam apenas a habilidade artística nos ornamentos da oratória:

Pois de que adianta que te tenhas mergulhado inteiramente nas fontes de Cícero, que nenhum escrito, nem dos gregos nem dos romanos te escape? Poderás, com efeito falar de modo ornado, com graça, com suavidade e de modo elevado; certamente não podes com gravidade, com austeridade, com sabedoria e, o que é mais importante de tudo, com uniformidade. ${ }^{25}$

Mas, sem traduzir-se, como ocorre no caso de Petrarca, em determinadas qualidades de estilo, o homem habil montaigniano surge como um ponto de culminância dessa tendência, avesso a conformar-se no registro exemplar de uma conciliação ideal entre eloquentia e sapientia. De fato, como bem observa Sergio Cardoso: "com Montaigne a afirmação dessa autonomia ganha significação mais ampla, mais desvencilhada de referências externas, mais centrada no próprio agente e em suas capacidades. ${ }^{26}$ Ainda assim, o desprezo à primeira vista tão enfático pela retórica em "Da Educação das crianças" revela-se bastante ambíguo afinal numa leitura mais atenta. Logo após destacar a inutilidade das artes da palavra Montaigne passa a discorrer sobre a maneira de escrever que mais lhe agrada, enumerando também, afinal, os elementos de um estilo que, a exemplo da "forma aberta" da epístola, estipulam a informalidade e naturalidade da conversação: "O falar que aprecio é um falar simples e natural, tanto no papel como na boca (...) livre de afetação, desordenado, descosido" (I, 26, 172). Consubstancia em seguida essa maneira num modelo que, sem abandonar a arte, maneja seus recursos visando simular sua ausência. Como nos diz, costuma ele mesmo tomar como exemplo a "displicência" [desbauche] no porte das vestimentas por parte de certos jovens que vê à sua volta:

o manto de banda, o capote em um ombro, uma meia mal esticada, o que manifesta uma altivez desdenhosa [fierté desdaigneuse] desses ornamentos estrangeiros e despreocupada [nonchalante] de artifícios. Mas acho-a ainda mais bem empregada 
na forma do falar. (...) fazemos bem em desviar-nos um pouco para o natural e o despretensioso. (Ibidem)

Sua fala "livre de afetação", portanto, não se confunde de modo algum com espontaneidade; é mesmo pensada e arranjada a partir do emprego da fierté desdaigneuse e da nonchalance calculada da juventude que o cerca: fruto de um desvio assumidamente intencional para o 'natural e o despretensioso'. Montaigne repõe assim a tradição da diligentia negligens, recomendada pela arte epistolar, "segundo a qual a negligência da elocução é efeito da diligência efetiva do discursador." ${ }^{27}$ Tendo tradicionalmente, como já vimos, a instrução - docere - como seu ofício próprio e o verdadeiro e o falso como objeto, é tarefa do sermo familiaris justamente dar primazia à inventio sobre a elocutio, sobressaindo pela dignidade das matérias - res - e não pela beleza das palavras - verba.

Mas, ao destacar sua matéria, Montaigne arrisca-se antes a perverter-se num ethos vicioso de presunção e orgulho, visto não se arrogar a capacidade de instruir e não constituir-se enquanto exemplo, portanto. De fato, a ética e a retórica antiga e humanista conceberam com maus olhos a forma discursiva em primeira pessoa quando não fosse adotada por personagens ilustres que pudessem servir à instrução dos homens. O falar de si afigurava-se, dessa perspectiva, como uso mal e frívolo da palavra ${ }^{28}$. Desse modo no proêmio de "Da Educação das crianças" Montaigne mostra-se profundamente consciente da frivolidade de seu discurso:

aqui estão meus humores e minhas opiniões; apresento-os como algo que está em minha crença [ma creance] e não como algo em que se deva acreditar [ce qui est à croire]. (...) Não tenho autoridade para ser acreditado, nem o desejo, sentindo-me demasiadamente mal instruído para instruir os outros.(I, 26, 148)

27 Martinho dos Santos, Marcos, "Arte dialógica e epistolar segundo as Epístolas morais a Lucílio" p.71. Sobre a diligentia negligens ver Cícero, Orator, 23, 78 e Petrarca, Fam. XVIII, 7.

28 Essa noção parece remontar à Ética a Nicômaco em que Aristóteles se refere a tal costume como incongruente com a grandeza de alma própria ao homem magnânimo - megalopsuchia -, já que destacado por sua aversão a "conversas fúteis" e por sua indiferença aos elogios alheios (IV, 1125 a.). Plutarco, por sua vez, assim se pronuncia sobre a questão na Moralia: "Falar de si diante de outrem para se atribuir qualquer mérito ou qualquer poder, todo mundo o declara em palavra, que é odioso e vil" e reserva tal prerrogativa exclusivamente a grandes homens de estado (VII, $539-547 \mathrm{f})$. Transposto para a Europa cristã da Idade Média, esse interdito ganharia novo ímpeto e dimensão ligado à crítica da vanitas, traço dos orgulhosos e dos ímpios. Mesmo Petrarca, em sua recuperação do gênero antigo da epístola tradicionalmente apropriado a tal prática, como já vimos - procura evitar que seu discurso pessoal afete a hybris da presunção quando na já citada carta proemial das Familiares, declara ter tido o cuidado de suprimir de seus escritos o excesso de dados privados que reconhecera e reprovara no modelo das cartas de Cícero, pois que seriam: "fastidiosos mesmo ao leitor curioso" $(I, 1,32)$. 
Com efeito, nesta autodefinição como "ma creance" oposta a "ce qui est à croire" o discurso ensaístico de Montaigne afirma-se substancialmente diverso do programa epistolar de Petrarca, em sua função do aconselhamento e instrução moral; que tem, como já vimos, na adaptação ao caráter do interlocutor seu preceito primeiro e fundamental de regulação. Em "Consideração sobre Cícero", Montaigne também reconhece que poderia ter sido "mais atento e mais firme" se tivesse um "endereço forte e amigo"; um "comércio" que lhe atraísse ao invés de voltar-se para o anonimato das "várias faces de uma multidão". "Inimigo jurado de toda falsificação", entretanto, recusa-se a forjar "nomes vazios" a quem dirigir-se e com quem entreter-se com "coisas sérias". Como nos diz: "tenho naturalmente um estilo familiar e privado, mas este é de uma forma toda minha, inapta aos contatos públicos, como em todas as formas é minha linguagem: demasiado concentrada [trop serré], desordenada [desordonné], fragmentada [couppé], particular [particulier]". (I, 40, 253). De fato, como observa Marc Fumaroli, a não exigência de adaptar-se à persona de um determinado leitor confere-lhe bem mais liberdade. Mas esta última, contudo, é importante ressaltar, está longe de cifrar-se afinal num ethos de meditação solitária que prescinde de interlocutores para voltar-se exclusivamente para si mesmo, já que, atenta o estudioso: "Não há animosidade em Montaigne contra a retórica nem nas 'Considerações sobre Cícero' nem em 'Da Educação das Crianças', mas ele subordina esta disciplina à formação do próprio entendimento e do 'jugement'." ${ }^{29}$ Para cumprir tal finalidade com efeito, o ensaio se vale largamente de procedimentos persuasivos, buscando redimir a falta de interlocutores e efetuar-se ao menos como esboço de um diálogo.

Isso nos leva forçosamente a retomar a frase final da "Advertência ao leitor" em seu curioso modo de dirigir-se aos leitores para excluí-los de seus desígnios: "sou eu mesmo a matéria de meu livro, não é sensato que empregues teu lazer em assunto tão frívolo e tão vão" (“Advis au Lecteur”, 3). Concordamos com André Tournon quando afirma que este conselho dissuasivo designa com bastante propriedade o programa diferenciado dos Ensaios, ou seja, o de "des-ensinar". Com efeito, procede daí uma determinada ética que postula uma relação de outra natureza com o leitor. Afinal, Montaigne "só despede aqueles demasiado dóceis, preparados segundo o contrato habitual para prover-se de verdades atestadas." ${ }^{30}$ Constrói por outro lado, em sua trama 
textual, uma outra classe de leitores, que aceitem seu convite fundamental à investigação; à ativação plena do próprio jugement.

Montaigne nomeia "ensaio" essa nova maneira de escrever, servindo-se, não por acaso de um termo que até então nada tinha a ver com as Belas letras. Derivado diretamente do substantivo latino exagium o termo francês essai designa essencialmente em seu século uma atividade do julgamento que não visa senão a si mesma, avaliando criticamente, medindo e pesando. Vinculada, assim, à noção de experimentação e movimento, punha-se fundamentalmente no registro do agente e não de uma finalidade objetiva e concreta que se realiza $^{31}$. O ethos que desponta de sua forma reflexiva e interrogativa é o do homem de jugement que se pretende contraposto ao do autor de obra bela e acabada, garantidora de glória imortal.

\section{III}

As proposições do ethos na epístola de Petrarca e no ensaio de Montaigne podem ser bem exemplificadas na prática, quando observamos os usos diferenciados que fazem de uma metáfora bastante significativa em seu tempo, tradicionalmente ligada à relação transformadora e criativa com as obras dos grandes autores, ou seja, a metáfora da produção do mel pelas abelhas. A imagem remonta pelo menos à carta 84 das epístolas a Lucílio de Sêneca, que a emula como modelo ideal de uma vida de estudos. Segundo o filósofo, devemos operar com os alimentos da inteligência um processo idêntico ao das abelhas, quando colhem o pólen das flores para delas produzir o mel, a partir de uma propriedade de seu organismo. Devemos, segundo Sêneca, discriminar os elementos colhidos das diversas leituras; aplicar-lhes todas as atenções de nossa inteligência para assimilá-los pelo espírito e transformálos então em um produto próprio, de sabor individual, diferente daqueles nos quais se inspirara ${ }^{32}$.

31 O dicionário etimológico d'Ernout-Meillet reformula as conclusões já tiradas por Varrão, quanto ao sentido aproximado dos verbos agere/facere, que se apresentam como uma sorte de universais a indicar a ideia de ação e processo. Segundo o referido dicionário, agere refere-se ao sujeito que age e, portanto, a uma atividade que se desenvolve, enquanto facere designa uma coisa que se faz, vinculado antes a um objeto que se torna. A palavra exagium, rica de implicações semânticas para a história do termo francês essai, é forma deverbal de exigere, que deriva diretamente de agere; é significativo o fato de que o sentido de exagium, conquanto se trate de um substantivo, não perde de vista a noção do dinamismo de uma atividade pensada em relação ao agente, designando o processo de avaliação e exame levado a cabo. Berlan, F. "Essai(s): Fortunes d'un mot et d'un titre.” p. 4.

32 Sêneca, op. cit., 84: 3-5. 
$\mathrm{Na}$ carta Da Invenção e do Engenho, a oitava do primeiro livro das Familiares, Petrarca repõe a metáfora de Sêneca e o sentido de sua lição, da assimilação ou digestão do alheio pelo espírito para a constituição de uma obra própria. É destacando então essa natureza ativa e renovadora da inventio que preceitua a imitação das abelhas ao seu correspondente, o também poeta Tommaso Caloiro: "tenhamos um estilo nem deste nem daquele, mas nosso, forjado a partir de vários" 33 ; desse modo reforça mais adiante o conselho, no final da carta:

a exemplo das abelhas esconde de tudo aquilo que se apresenta as coisas mais bem escolhidas na colméia do coração, poupa-as com diligência e conserva-as tenazmente para que nada se perca se for possível. E cuida para que não permaneçam contigo tais quais tu as colheste, de fato não haveria glória para as abelhas se não convertessem em outra coisa melhor e diversa aquilo de que se apropriaram. (...) daí pois, jorrarão aquelas obras as quais com excelente razão tanto a idade presente quanto a vindoura a ti atribuirão. ${ }^{34}$

Montaigne reinterpreta a mesma metáfora em "Da Educação das crianças”. Ela aparece em sua proposta pedagógica, como reflexo da relação que ele próprio estabelece com os autores antigos que apresenta, recorrendo à imagem das danaides ${ }^{35}$. Conforme nos diz então, não travara relações com nenhum livro sólido exceto de Sêneca e de Plutarco, nos quais se abastece, contudo, como as danaides: "enchendo e vertendo sem cessar [remplissant et versant sans cesse]. Fixo alguma coisa disso neste papel; em mim praticamente nada." (I, 26, 146)

Com efeito, a imagem das danaides vem excluir desde já do comércio com os antigos a figura do bom escritor que, em Petrarca, "esconde", "poupa" e "conserva" com diligência os materiais coligidos de suas leituras. Ao invés de armazená-los na memória e selecioná-los de modo adequado para constituir uma obra nova que lhe garantisse glória imortal, opera de acordo com a imagem das danaides, esquecendo-se de sua origem para naturalizar o alheio como próprio.

Desse modo, quando, pouco adiante, Montaigne retorna a aconselhar a imitação das abelhas, como modo da relação ideal com os antigos em seu programa pedagógico, investe-a de novo significado. Identifica então o mel, resultado do processo de assimilação ou digestão das opiniões de outros,

33 Petrarca, op. cit., I, 8, 5 .

34 Idem, 23.

35 Figura da mitologia grega: Danaides são as cinquenta filhas de Danao, irmão de Egito, punidas no hades por assassinarem seus maridos, condenadas a encherem de água uma jarra com furos. 
menos à produção de uma obra concreta, do que a um estado da faculdade de julgar, a afirmar-se em sua plena autonomia: "uma obra toda sua: a saber, seu julgamento. Sua educação, seu trabalho e estudo visam tão somente a formá-lo." (Idem) “Ouvrage de jugement” parece ser bem o caso dos Ensaios: afirmada enquanto obra concreta como fosse consequência ou veículo da atividade do jugement, forma por excelência do ethos de um homem "habil".

\section{Referências bibliográficas}

ARISTÓTELES. The Art of Rhetoric, Tradução John Henry Freese. London, Loeb Classical Library, 2006.

BERLAN, Françoise. "Essai(s): Fortunes d'un mot et d'un titre", In: L'Essai: Metamorphoses d'un genre, Tolouse, Presses Universitaires Du Mirail, 2002.

BIRCHAL, T. O eu nos Ensaios de Montaigne. Belo Horizonte: Editora da UFMG, 2007.

CARDOSO, S. "Montaigne: uma ética para além do humanismo" In: O que nos faz pensar n. 27, Cadernos do Departamento de Filosofia da Puc-Rio, 2010, p. 257-278,. DOTTI, Ugo. Vida de Petrarca. Campinas, Unicamp, 2006.

FRIEDRICH, Hugo, Montaigne, Gallimard, 1968.

FUMAROLI, Marc. "Genèse de l'épistolographie classique: Rhétorique humaniste de la lettre" In: Revue d'Histoire Littéraire, v. 78, 1978, p. 892-894.

"Les Essais de Montaigne: l'éloquence du for intérieur" In: $L a$ Diplomatie de l'esprit, Paris, Gallimard, p. 125-163, 1998.

GARIN, Eugênio. L'Education de l'Homme Moderne (1400-1600). Paris: Fayard, 1968.

GOYET, Francis. "Montaigne and the Notion of Prudence" In: The Cambridge Companion to Montaigne, Cambridge University Press, p. 118-142, 2005.

MARTINHO DOS SANTOS, Marcos. "Arte dialógica e epistolar segundo as epístolas morais a Lucílio” In: Letras Clássicas n. 3, Humanitas FFLCH/USP, p. 45-95, 1997. MESNARD, Pierre. "Le Commerce épistolaire comme expression sociale de l'individualisme humaniste", In: Individu et Societé a la Renaissance, Bruxelles/ Paris, Presses Univ. de Bruxelles, p. 17-31, 1967.

MONTAIGNE, M. Les Essais. Édition de Pierre Villey avec appendices, sources, index. Paris: Quadrige/Presses Universitaires de France, 1988.

PETRARCA. Lettres Familières. Paris, Belles Lettres, 2002. . Epistola Posteritati, In: ENENKEL, Karl. Modelling The Individual, Amsterdam-Atlanta, Ed. Rodopi, 1998, p. 243-283.

SÊNECA, L. A. Cartas a Lucílio. Lisboa: Fundação Calouste Gulbenkian, 1991.

STRUEVER, Nancy. Theory as Practice: Ethical Inquiry in the Renaissance, Chicago, University of Chicago Press, 1992.

TIN, Emerson. A Arte de escrever cartas, Campinas, Unicamp, 2005.

TOURNON, André. Montaigne. São Paulo, Discurso Editorial, 2004. 